\section{Charting a Course for the International Union of Materials Research Societies}

For all the delegates and members of the Founding Adhering Bodies, it was indeed an exciting moment, on November 27, 1990 , to realize that after years of planning we had, at last, formed the International Union of Materials Research Societies (IUMRS). It is my honor and a privilege to serve as the first president of IUMRS, and I look forward to working closely with the members of the executive committee and all the delegates from our member societies.

Following the objectives of IUMRS as stated in its statutes, we intend to make every attempt to fulfill our vision. In the next few years we will focus our efforts in the following areas-programming, communication, and research cooperation. At the next IUMRS meeting in Strasbourg, France (May 1991), plans will be laid to im-

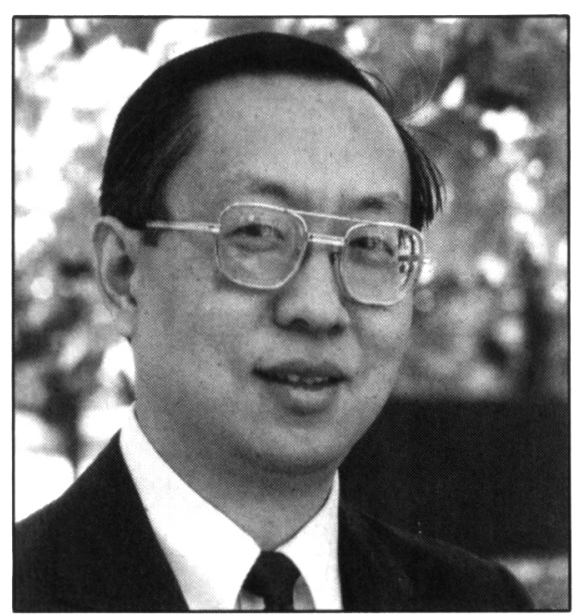

R.P.H. Chang

President, IUMRS plement some of the ideas that we will develop collectively.

- Programming: What brought us together was, in fact, the co-sponsorship of international materials conferences and meetings. In 1988 we had our first international conferences on advanced materials (ICAM-88) and on electronic materials (ICEM-88) in Japan. That initial success led us to continue these series of conferences, ICEM-90 in the United States and ICAM-91 in Strasbourg. No doubt these conferences will be continued throughout this decade. In addition, we are developing a series of international workshops on materials. The first workshop, "Science and Technology of Thin Films for the 21st Century," will be held July 28-August 2, 1991, at Northwestern University in the United States. A commission in programming will be established this year to help coordinate international meetings.

- Communication: A vital link to materials scientists and engineers worldwide involves rapid and timely communication. The MRS Bulletin has been doing an excellent job in fulfilling part of our needs. Starting with this issue, the Bulletin will dedicate a section to IUMRS news and information. In addition, the Bulletin's Calendar is available for listing all materials-related meetings. I encourage the member societies to make good use of this opportunity.

A medium for rapid publication (within 1 to 2 months) of materials research in the form of a communiqué is very desirable. The development of electronic communications equipment has made such a goal achievable; however, this undertaking requires the effort and cooperation of many societies. IUMRS is the appropriate body to consider such a project. Another project worth considering involves satellite linking of important meetings and events. A commission on communication will be formed to discuss and plan these potential new ventures for IUMRS.

- Research Cooperation: The hallmark of materials research societies is interdisciplinary research involving the participation of scientists and engineers from various disciplines. IUMRS can add another dimension to this goal by fostering international research cooperation and aiding the establishment of experimental projects which require multinational participation.

The success of IUMRS will come through cooperation and participation. I look forward to the many challenges ahead.

R.P.H. Chang President, IUMRS 